\section{Temperature dependant structural changes in thin films of random semifluorinated PMMA copolymers}

Dieter Jehnichen, ${ }^{1, a)}$ Peter Friedel, ${ }^{1}$ Romy Selinger, ${ }^{1}$ Andreas Korwitz, ${ }^{1}$ Martin Wengenmayr, ${ }^{2}$ Andreas Berndt, ${ }^{1}$ and Doris Pospiech ${ }^{1}$

${ }^{1}$ Leibniz-Institut für Polymerforschung Dresden e.V., Hohe Str. 6, D-01069 Dresden, Germany

${ }^{2}$ Technische Universität Chemnitz, Straße der Nationen 62, D-09111 Chemnitz, Germany

Semifluorinated (SF) side chain polymers show phase separation between polymer backbone and SF side chains. Due to strong interaction between SF segments the side chains determine the structure behaviour strongly, often resulting in layered structures in which backbones and layers of SF side chains alternate. The interest in this work was directed to find out the dependence of these structures on concentration of SF side chains. Thin films of random copolymers consisting of methylmethacrylate (MMA) and semifluorinated side chain methacrylate (SFMA) segments and with different fluorine content in the perfluoroalkyl side chains (abbreviated as $\mathrm{H} 10 \mathrm{~F} 10$ and $\mathrm{H} 2 \mathrm{~F} 8$ ) were prepared by spin-coating. Phase separation and structure changes were initiated by external subsequent annealing. Corresponding bulk material served as basic information. Generation of ordered structures and variation of film parameters were observed using different X-ray scattering methods (XRR, GIWAXS, and GISAXS). The phase behaviour in bulk is governed by the SF side chain amount and their specific fluorine content which control the self-organization tendency of SF side chains. Additionally, the confinement in thin films generates an orientation of side chains normally to film surface.

Keywords: T-dependant X-ray scattering, GISAXS, phase separation, thin films, random copolymers, semifluorinated polymer

a) Author to whom correspondence should be addressed. Electronic mail: djeh@ipfdd.de

\section{INTRODUCTION}

Semifluorinated (SF) side chain polymers show a structure behaviour which is characterized by phase separation between polymer backbone and SF side chains (e.g., Höpken and Möller, 1992; Wang et al., 1997), driven by huge Flory-Huggins interaction parameters. As a result of the strong interaction between the fluorinated segments, e.g. perfluoroalkyl groups, the side chains determine the structure behaviour strongly (Friedel et al., 2000; Gottwald et al., 2002) and influence physical parameters and application properties significantly (Gopalan et al., 2002; Appelhans et al., 2005; Tsuwi et al., 2007). In general, sufficiently long SF side chains are organized in ordered structures (Li et al., 2002; Busch et al., 2007). The internal microphase separation leads mostly to smectic layered structures in which the backbones and layers of SF side chains alternate (Jehnichen et al., 2001; Pospiech et al., 2003b). Former experiments examined in detail the behaviour of different polymers with $\mathrm{H} 10 \mathrm{~F} 10$ side chains [-O- $\left.\left(\mathrm{CH}_{2}\right)_{10}-\left(\mathrm{CF}_{2}\right)_{10}-\mathrm{F}\right]$ (Pospiech et al., 2001; Pospiech et al., 2003a). Combination of different scattering methods and thermal treatments yielded in understanding the special side chain structure characterized by interdigitation and tilt of side chains (Jehnichen et al., 2004; Jehnichen et al., 2007). Incorporation of H10F10 side chains lead in all types of polymer backbones used (aromatic and aliphatic polyesters, polysulfones, polypropylene copolymers) to distinguished phase separation with layered structures having similar $d$-spacings (Jehnichen et al., 2007; Jehnichen et al., 2011). Additionally, such structures gave rise to unusually low surface free energies (Wang et al., 1997; Grundke et al., 2001; Pospiech et al., 2003b; Galli et al., 2005) due to the formation of a similar structure in the surface region attended by enrichment of F-containing segments in that layer (Pospiech et al., 2003c)

The interest in this work was directed to find out the dependence of the structure behaviour on the fluorine concentration and side chain length. Random copolymers consisting of methylmethacrylate (MMA) and semifluorinated side chain methacrylate (SFMA) segments were synthesized by radical polymerization varying the structure of the side chain: H10F10 and H2F8 [-O- $\left.\left(\mathrm{CH}_{2}\right)_{2}-\left(\mathrm{CF}_{2}\right)_{8}-\mathrm{F}\right]$ (Figure 1 and Table I). Thin films with roughly comparable films thicknesses were prepared by spin-coating.

The phase separation and its changes were initiated by external subsequent annealing of thin films (different procedures). Appropriate temperature steps were determined investigating the corresponding bulk material via combined T-SAXS / T-WAXS showing characteristic phase transition temperatures. Generation of ordered structures and variation of film parameters were observed using different X-ray scattering methods (XRR, GIWAXS and GISAXS). 


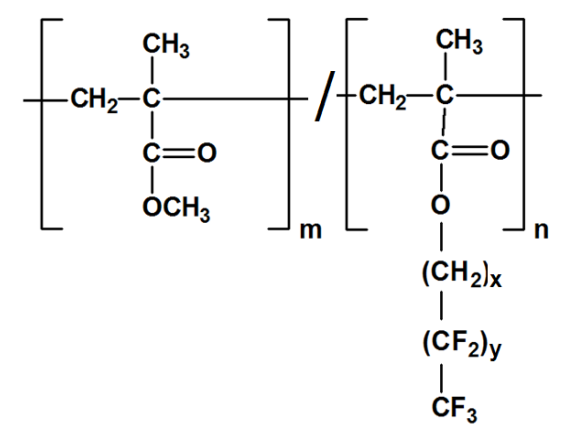

Figure 1: Chemical formula of random P(MMA/SFMA-HxFy+1) copolymers with $(\mathrm{x}, \mathrm{y})=$ $(2,7)$ and $(10,9)$ under investigation.

TABLE I. Sample overview.

\begin{tabular}{llllr}
\hline \hline Sample & Sample form & SF side chain & $\begin{array}{l}\text { SF concentration } \\
(\mathrm{mol} \%)\end{array}$ & $\begin{array}{l}\text { Molar mass } M_{\mathrm{w}} \\
(\mathrm{g} / \mathrm{mol})\end{array}$ \\
\hline H2F8-41 & bulk & H2F8 & 41 & 18.100 \\
H2F8-71 & bulk & H2F8 & 71 & 5.000 \\
H10F10-38 & bulk & H10F10 & 38 & 22.000 \\
H10F10-66 & bulk & H10F10 & 66 & 6.700 \\
H2F8-37 & film & H2F8 & 37 & 64.000 \\
H2F8-72 & film & H2F8 & 72 & 5.900 \\
H10F10-36 & film & H10F10 & 36 & 27.600 \\
H10F10-54 & film & H10F10 & 54 & 19.000 \\
\hline
\end{tabular}

\section{EXPERIMENTAL}

\section{A. Sample preparation}

\section{Synthesis}

Random P(MMA/SFMA) copolymers were synthesized by radical polymerization in bis(trifluoromethyl)benzene (BFMB). Therefore, destabilized monomers, solvent BFMB and initiator azobis(isobutyro)nitrile (AIBN) were filled into a dried Schlenk flask. It was purged and deoxygenated by three freeze-thaw cycles. The flask was placed into a heating bath at $80{ }^{\circ} \mathrm{C}$ for polymerization under stirring for $4 \mathrm{~h}$. The flask was cooled down to room temperature and then a mixture of BFMB and chloroform $(1 / 1 \mathrm{v} / \mathrm{v})$ was added to dilute the solution. The solution was precipitated into methanol, filtered off and dried in vacuum at $50{ }^{\circ} \mathrm{C}$ for $12 \mathrm{~h}$ to obtain a white solid. Relative averaged molar masses $\mathrm{M}_{\mathrm{w}}$ and $\mathrm{M}_{\mathrm{n}}$ were determined by size-exclusion chromatography (SEC) yielding values relative to narrow distributed PMMA standards.

\section{Film preparation}

Thin polymer films were prepared by spin-coating (2000 rpm / $30 \mathrm{~s}$ ) of $2 \mathrm{wt} \%$ filtered (through $0.45 \mu \mathrm{m}$ Teflon filter) polymer solution in BFMB onto pre-cleaned silicon wafers. The films were dried at $30^{\circ} \mathrm{C}$ for $24 \mathrm{~h}$ in vacuum. For XRR and GIWAXS experiments, offline annealing (in subsequent steps up to $160{ }^{\circ} \mathrm{C}$ considering transition temperatures of the copolymers) was performed, followed by a fast cooling to room temperature.

\section{B. X-ray scattering experiments}

\section{T-SAXS / T-WAXS}

Combined temperature-dependant small- and wide-angle X-ray scattering (T-SAXS / TWAXS) in transmission geometry were carried out at the Soft Condensed Matter Beamline A2 (HASYLAB @ DESY Hamburg, $\lambda_{\mathrm{A} 2}=0.15 \mathrm{~nm}$ ) applying linear detectors (both mounted perpendicular to the primary beam, detector channels correspond to the scattering vector with different offsets concerning SAXS and WAXS detector). Oven experiments were executed by heating/cooling rates of $3 \mathrm{~K} / \mathrm{min}$ or by fast cooling.

\section{XRR and GIWAXS}

X-ray reflectometry (XRR) was carried out at diffractometer XRD T/T (GE Inspection Technologies Ahrensburg, Germany) in symmetric step-scan mode with $\Delta 2 \Theta=0.01^{\circ}$ and $t=$ $3 \mathrm{~s}$ ( $\mathrm{Cu} K \alpha$ radiation). Grazing incidence wide-angle X-ray scattering (GIWAXS) was carried out at the same diffractometer XRD T/T in asymmetric step-scan mode with $\Delta 2 \Theta=0.05^{\circ}$ and $t=20 \mathrm{~s}$ ( $\mathrm{Cu} K \alpha$ radiation) and grazing angle $0.7^{\circ}$ (irradiated film area $10 \times 15 \mathrm{~mm}^{2}$ ). The layer distances ( $d$-values) were calculated using Bragg's law onto the layer reflections (maximum positions in $2 \Theta$ ).

\section{T-GISAXS}

Temperature-dependant grazing incidence small-angle X-ray scattering (T-GISAXS) was carried out at the Beamline BW4 (HASYLAB @ DESY Hamburg, $\lambda_{\mathrm{BW} 4}=0.138 \mathrm{~nm}$ ) applying the area detector MarCCD (Marresearch Inc., USA). 2D-pattern within incidence angles $\alpha_{\mathrm{i}}\left(0.03^{\circ}-0.30^{\circ}\right.$ ), close to the critical angles $\alpha_{c}$ (polymer film, e.g., pure PMMA: $\alpha_{\mathrm{c}} \approx$ $0.146^{\circ}$; substrate $\mathrm{SiO}_{\mathrm{x}}: \alpha_{\mathrm{c}} \approx 0.20^{\circ}$ ) were accumulated with sufficiently high measuring time to find an optimal $\alpha_{\mathrm{i}}$ for oven experiments, which were executed by heating/cooling rates of 3 $\mathrm{K} / \mathrm{min}$ or by fast cooling. 


\section{RESULTS AND DISCUSSION}

\section{A. Bulk behaviour}

Figures 2 and 3 illustrate the temperature-dependant scattering behaviour of the bulk material H10F10-38 starting from the as-synthesized state. This state is characterized as powder-like particles that precipitate from synthesis. The first heating run shows the formation to be seen at the spatial separation of the chemically incompatible segments and improvement of the phase morphology as seen as appearance of well-shaped reflections. At temperatures higher than $T_{\mathrm{m}}$ (side chain melting) and lower than $T_{\mathrm{i}}$ (isotropization), a typical smectic layer structure (see Figure 2 ) with negative coefficient of linear expansion of the layer distance $\left(1^{\text {st }}\right.$ and $2^{\text {nd }}$ order reflection of the side chain layers changing going from $d \sim 4.7 \mathrm{~nm}$ to $4.2 \mathrm{~nm}$ ) was found. This behaviour resembles that of semifluorinated polyesters (Jehnichen et al., 2004 and 2007). At $T_{\mathrm{i}}$ the layer structure is lost. Only an "amorphous-like" broad maximum is visible until $150^{\circ} \mathrm{C}$, which is above the glass transition temperature $T_{\mathrm{g}}$ of the base main chain PMMA). The fluorinated part of the SF side chains are comparable to hexagonally packed PTFE chains in helix conformation. In the corresponding WAXS pattern (see Figure 3) this lateral arrangement disappears above $T_{\mathrm{m}} \sim 57{ }^{\circ} \mathrm{C}$ and is re-generated in the cooling cycle below $T_{\mathrm{m}}$. For $\mathrm{T}>T_{\mathrm{m}}$, only a broad amorphous scattering maximum remains.

$$
T_{m} \quad T_{1}
$$$$
\mathbf{T}_{\text {g,PMMA }}
$$$$
\mathbf{T}_{\mathrm{m}}
$$

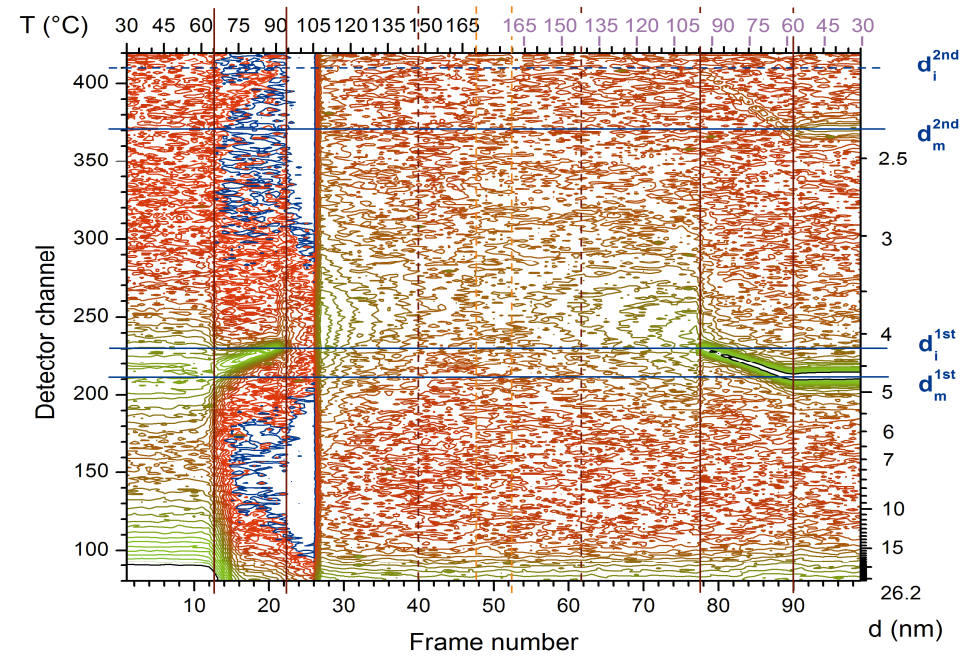

Figure 2: (Colour online) T-SAXS - Contour plot of sample H10F10-38 (as-synthesized) Scattering intensity plot (in miscolour) $\log (I)$ vs. $T$ and vs. $d$.
Copolymers with H2F8 side chains show a much weaker pronounced layer formation with a $d$-value of $\sim 3.0 \mathrm{~nm}$ corresponding to the shorter side chain. Smectic layers as well as lateral correlation between the side chains could not be observed. This was expected due to the shorter SF segment of the side chain. This result is valid for both low and high SF comonomer concentrations. For both side chain types, the lateral correlation effects are significantly lower in comparison to the corresponding diblock copolymers having comparable SF concentration (Jehnichen et al., 2011). All bulk data are summarized in Table II.

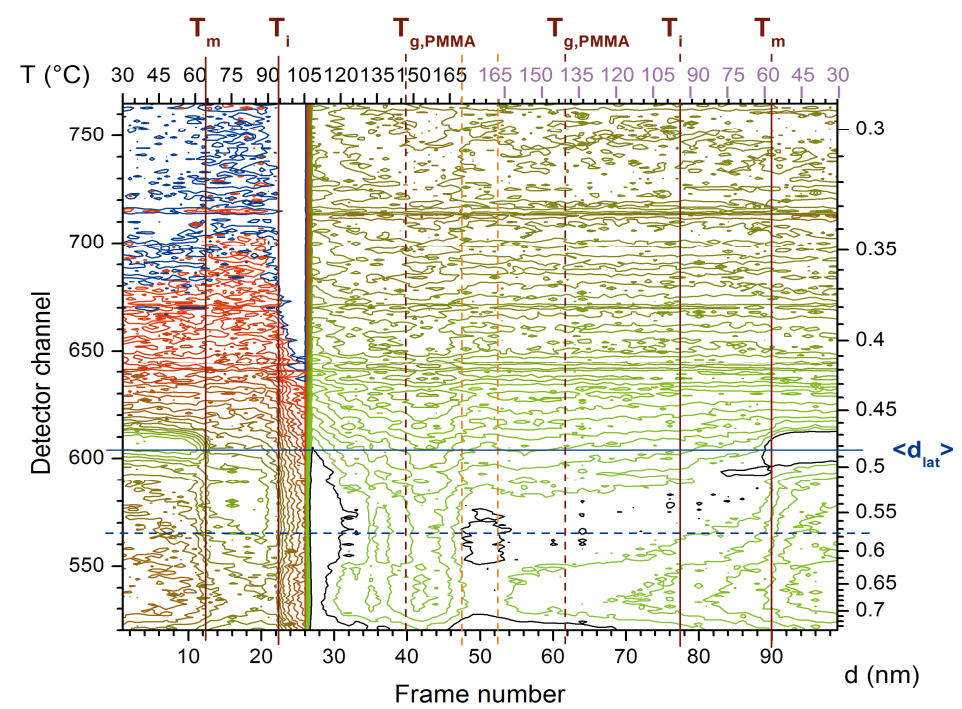

Figure 3: (Colour online) T-WAXS - Contour plot of sample H10F10-38 (as-synthesized) Scattering intensity plot (in miscolour) $\log (I)$ vs. $T$ and vs. $d$.

TABLE II. Results of $T$-dependant scattering experiments of the investigated samples (bulk parameters from $1^{\text {st }}$ cooling run).

\begin{tabular}{|c|c|c|c|c|c|}
\hline & Sample & $\begin{array}{l}\text { H2F8-41 } \\
\end{array}$ & $\overline{\text { H2F8-71 }}$ & H10F10-38 & $\overline{\text { H10F10-66 }}$ \\
\hline$T\left({ }^{\circ} \mathrm{C}\right)$ & & T-SAXS & & & \\
\hline 95 & Layer distance & -- & -- & 4.18 & 4.05 \\
\hline 30 & $d(\mathrm{~nm})$ & 3.0 & 2.8 & 4.65 & 4.70 \\
\hline & & T-WAXS & & & \\
\hline 30 & $\begin{array}{l}\text { Mean chain distance } \\
<d_{\text {lat }}>(\mathrm{nm})\end{array}$ & 0.520 & 0.525 & 0.485 & 0.490 \\
\hline
\end{tabular}




\section{B. Thin films}

\section{XRR and GIWAXS}

As-prepared films (film thicknesses from 74 to $90 \mathrm{~nm}$ ) show very low roughness and good preparation reproducibility. The as-prepared films were stepwise annealed and after fast quenching offline examined by XRR. In the temperature range of $T_{\mathrm{m}}$ the generation of the layered structure shows a different behaviour dependant on the side chain type and concentration. In the case of H10F10 side chains (Figure 4 for lower H10F10 concentration), the layer arrangement starts as in the bulk at $T_{\mathrm{m}}<T<T_{\mathrm{i}}$. The layer distance (found for the second annealing step $80{ }^{\circ} \mathrm{C}$ ) is $4.2 \mathrm{~nm}$ (about $0.4 \mathrm{~nm}$ smaller compared to the bulk value after complete heating/cooling cycle). For higher annealing temperatures (up to $T=160{ }^{\circ} \mathrm{C}$ ) more or less frozen states were found accompanied by degradation of the film which was deduced from the higher roughness. In principle, this is confirmed by films having higher H10F10 concentration, but much lower film thicknesses (14 nm). Certainly, the discussion of details with respect to this is difficult due to the restricted film thickness (only $\sim 3$ layers can be formed by phase separation: the lower one in interaction to the silica substrate, the upper one in interaction with air)

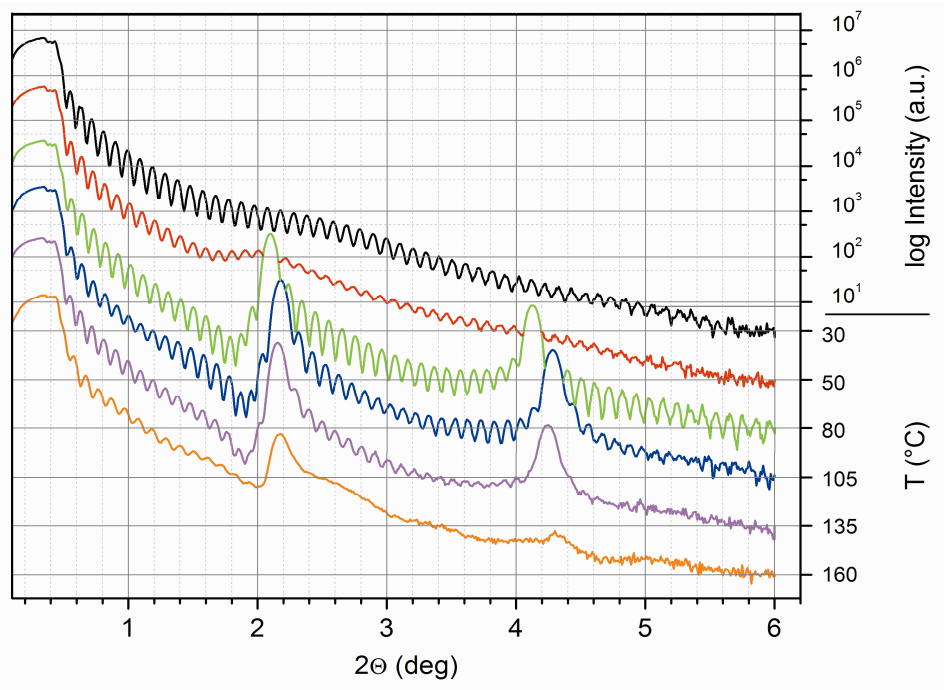

Figure 4: (Colour online) XR curves of sample H10F10-36 (at room temperature) after subsequent annealing (measured after quenching to room temperature).

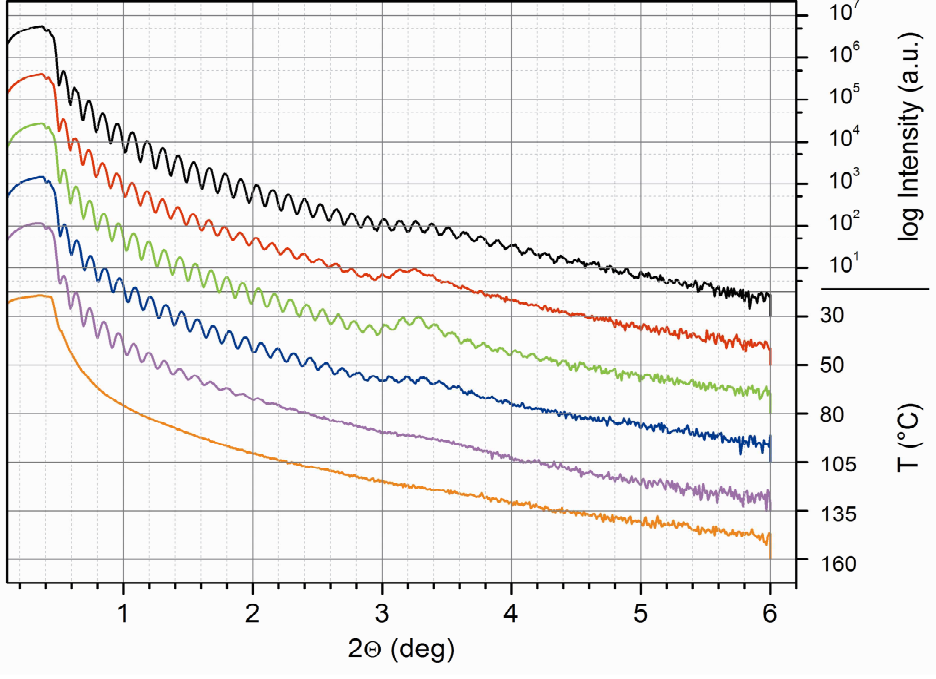

Figure 5: (Colour online) XR curves of sample H2F8-72 (at room temperature) after subsequent annealing (measured after quenching to room temperature).

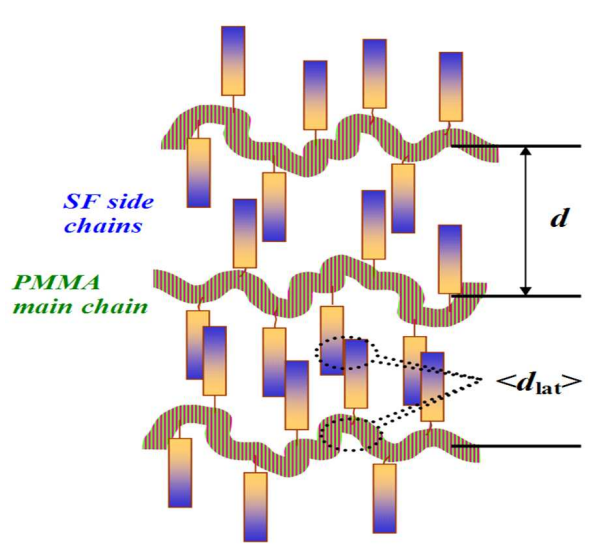

Figure 6: (Colour online) Schematically simplified structure of P(MMA/SFMA) copolymers with well-ordered layers.

Inspired by an obvious model based on both chemical structure and compatibility behaviour of the different segments (Figure 6), a simple model which is characterised as a stack of repeating sublayers was chosen to fit the experimental XRR curves. As a preliminarily result was found a stack of 20 repeating units verifying the Bragg reflection with $d=4.28 \mathrm{~nm}$ and 
internal substructure of a PMMA-like sublayer with $d_{\mathrm{mch}}=2.70 \mathrm{~nm}$ (representing the main chain and a part of the alkyl segment of the side chain) and a PTFE-like sublayer with $d_{\text {sch }}=$ $1.58 \mathrm{~nm}$ (representing mainly the perfluorinated part of the side chain). The ratio $d_{\text {mch }}$ to $d_{\text {sch }}$ is in line with the assumed model and the spatial parameters fit well the film thickness of 85.6 $\mathrm{nm}$. The adapted electron densities in the respective sublayer are reduced by about $10 \%$ in relation to the bulk parameters of PMMA and PTFE, respectively. The discussed numerical values are valid for the XRR curve of sample H10F10-36 measured after annealing with 80 ${ }^{\circ} \mathrm{C}$ (compare Figure 4).

As expected from the bulk results, H2F8 copolymer films show a different behaviour (Figure 5). In the case of lower H2F8 concentration no layers are generated during the annealing process. Only a very weak and broad scattering maximum occurs at the position where the Bragg maximum would be expected. At temperatures higher than $T_{\mathrm{g}}$ of the main chain the film parameters reflect thermal degradation showed by increasing roughness. The layer arrangement in films from copolymers with higher concentration starts at $T \sim 50{ }^{\circ} \mathrm{C}$. The layer generation is significantly stronger compared to the bulk and appears at lower temperatures. But, the stability of the layered structure at higher annealing temperatures is lower (which can also be influenced by the quenching process from melt). The layer distance $d$ was estimated to be $\sim 2.8 \mathrm{~nm}$ (from Bragg maximum) and is about $0.3 \mathrm{~nm}$ lower as in the bulk.

The GIWAXS experiment exhibits a broad scattering maximum corresponding to superimposed scattering parts from non-ordered main chains PMMA and the not well-ordered $\mathrm{SF}$ side chains in pseudo-hexagonal packing. Thus, this maximum corresponds to an intermolecular distance which represents basically a "mean chain distance" $\left\langle d_{\mathrm{lat}}>\right.$ considering the main chains, the side chains and their arrangements to each other (compare Figure 6). For copolymers with H10F10 side chains the maximum corresponds stronger to a distance $\left\langle d_{\text {lat }}\right\rangle$ comparable to poly(tetrafluoro ethylene) chains in well-crystallized PTFE homopolymer $\left(\left\langle d_{\text {lat }}\right\rangle \approx d_{\text {hex }(100)}=0.489 \mathrm{~nm}\right)$. The tendency to generate a pseudo-crystalline order (as found in bulk experiments) is significantly reduced in thin films. There was also no improvement by annealing. In samples with H2F8 side chains (i.e., shorter side chain and lower F content) this small ordering effect is much lower. Thus, the distance $\left\langle d_{\mathrm{lat}}\right\rangle$ is smaller and rather similar to that of PMMA. All data $<d_{\mathrm{lat}}>$ experimentally found by T-GIWAXS are listed in Table III and those fond by T-WAXS in Table II yet. Due to the orientation of the layer structure and the arrangement of the side chains nearly perpendicular to the substrate (see discussion of GISAXS, below) the GIWAXS intensity caused by these structures is decreased additionally.

\section{T-GISAXS}

The technique of grazing incidence small-angle X-ray scattering (GISAXS) was successfully applied to soft condensed matter samples in the thin-film geometry since several years (Rauscher et al., 1995; Müller-Buschbaum, 2009). Nanostructures parallel and perpendicular to the sample surface are observable in thin diblock copolymer or other micro-phase separated polymer based films (Müller-Buschbaum, 2003; Busch et al., 2006). The basic ideas and possibilities of the GISAXS technique are illustrated in Figures 7a and $b$
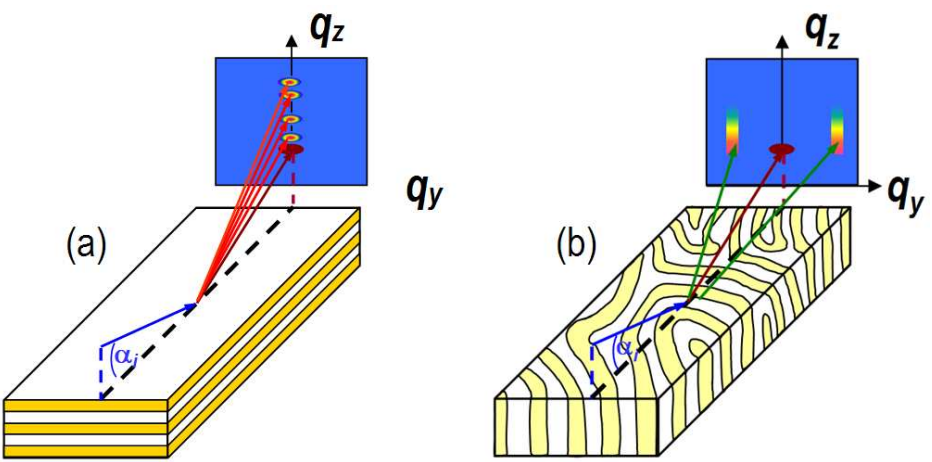

Figure 7: (Colour online) Schematic drawing of scattering geometries for illustration of GISAXS experiments of a thin film structure with lying layers ((a) - parallel to substrate; sample in $x, y$ plane and scattering plane defined by $x, z$ plane) and standing layered structures (b) - perpendicular to the substrate). The intensity trace on the blue screen in (a) (detector: $y, z$ plane) corresponds to the detector scan (in-plane scan) $I=I\left(q_{\mathrm{z}}\right)$ (vertical slices, $q_{\mathrm{y}}=0$ ), which basically probes structures perpendicular to the sample surface. The intensity trace on the blue screen in (b) corresponds to the out-of-plane scan $I=I\left(q_{\mathrm{y}}\right)$ (horizontal slices, e.g. $q_{\mathrm{z}}=$ $q_{\mathrm{cr}}$, conform to the critical angle $\alpha_{\mathrm{cr}}$ of one copolymer component), which basically probes lateral structures in the sample surface. The corresponding $d$-values of the scattering maxima (correlation peaks) in the intensity scans reflect spatial structure parameters as projection onto the scattering vector direction. The specular reflected beam $\left(\alpha_{\mathrm{i}}=\alpha_{\mathrm{f}}\right)$ was shielded by a beam stop, whereas the transmitted beam (close to the primary beam direction) was absorbed by the sample. The GISAXS pictograms were adapted from Busch (2003).

Figures 8 (a) to 8 (f) depict the $T$-dependant scattering behaviour of the $89 \mathrm{~nm}$ thin film consisting of H10F10-36 as example for the polymer films under investigation. The chosen detector area of the GISAXS pattern contains the direct beam position (lower edge) and cover the scattering area for lateral $d$-values $>3.9 \mathrm{~nm}$ and normal $d$-values $>2.8 \mathrm{~nm}$.

The as-prepared sample state (room temperature) shows weak lateral correlation peaks at 4.72 $\mathrm{nm}$ and a broad halo in the detector scan. During heating the lateral peaks disappear and for $T$ 
$>84^{\circ} \mathrm{C}$ a strong Bragg reflection at $4.69 \mathrm{~nm}$ is generated in the detector scan. This reflection shows a marked sickle-like azimuthal intensity distribution proving the unidirectional orientation of the layers parallel to the substrate (lying layers) as well as narrow deviation behaviour. The formerly standing layers are newly oriented. Following this model, the existence of nearly perpendicularly standing SF side chains can be concluded. Additionally, a second scattering maximum occurs at higher scattering angles which cannot be understood by usual application of Bragg's law. Different scenarios may be discussed: (a) The second scattering maximum could be caused by multiple reflection effects in the film morphology, too. So it can be imagined to get reflections from the film surface directly as well also from the interface to the silicon substrate. In films with excellent geometric parameters versus the irradiated area a standing wave field cannot be excluded. To clarify this reflectivity behaviour, GISAXS experiments should be performed at different film thicknesses in dependence on both $T$ and incident angle $\alpha_{\mathrm{i}}$ in detail, which has to be varied from $\alpha_{\mathrm{i}}<\alpha_{\mathrm{c}}$ to $\alpha_{\mathrm{i}}>\alpha_{\mathrm{c}}$ and considering the fluorine content of the film material. These measurements were not possible in the frame of the work discussed here. (b) As suggested by T-SAXS, two different layer structures could be coexistent in a distinct temperature range between room temperature and isotropization temperature ( $\mathrm{RT} \ldots T_{\mathrm{m}} \ldots T_{\mathrm{i}}$ ), if it can be assumed that the smectic layer structures with $d$-values between 4.2 and $4.7 \mathrm{~nm}$ are frozen or hindered to relax. (c) Furthermore, another possibility to describe this phenomenon is to treat it in a similar manner like diffraction of random copolyesters (Mitchell and Windle, 1985). It is imaginable that the polymer chains stand like brushes on the substrate with liquid-like lateral correlation to each other. Secondly, the polymer chains P(MMA/SFMA) have random distribution of the comonomers MMA and SFMA and thus fill out the film thickness completely. A model of randomly distributed chains is able to cause diffraction patterns similar to those found in Figure 8 (c) for example. In summary, the validation of (a) may be performed representing the simplest case.

At $T>105{ }^{\circ} \mathrm{C}$ (i.e., $T>T_{\mathrm{i}}$ ) no scattering structures can be observed. In the cooling cycle to room temperature, the generation of a highly oriented layered structure starts again at $T<90$ ${ }^{\circ} \mathrm{C}$ with $d$-values decreasing from 4.80 to $4.52 \mathrm{~nm}$. Below $T=66{ }^{\circ} \mathrm{C}$, a marked orientation distribution around the substrate normal and lateral correlation peaks occur again. A quite similar behaviour was found for the $14 \mathrm{~nm}$ thin film consisting of H10F10-54. As expected, the scattering intensities are significantly lower. In each case, the actual layered structure in the thin films was initiated by the different temperature treatments, only. All $d$-values found in GISAXS correlate well with those of T-SAXS.
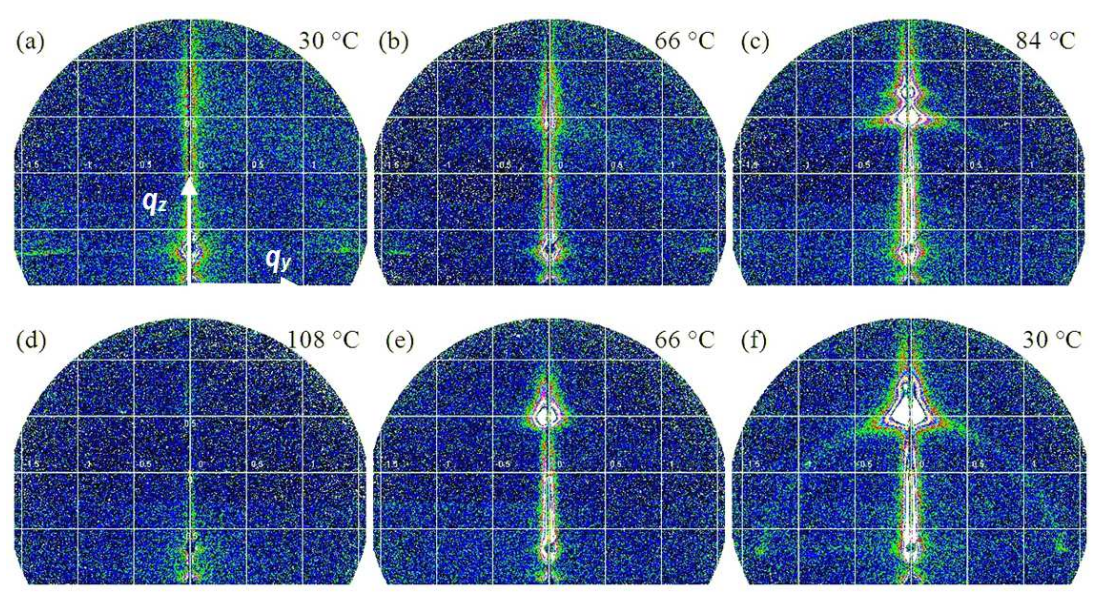

Figure 8: (Colour online) Representative GISAXS 2D patterns of sample H10F10-36 at different temperature ((a)-(d) heating, (e)-(f) cooling). Scattering intensity plot (false colour representation) $\log (I)$ vs. $q$ (mesh size $\Delta q=0.5 \mathrm{~nm}^{-1}$; primary beam position: in the middle of the lower bound of the 2D GISAXS patterns, see (a)).

TABLE III. Structure and morphology parameters from different scattering methods

\begin{tabular}{|c|c|c|c|c|c|}
\hline \multicolumn{2}{|l|}{ Sample } & $\begin{array}{l}\text { H2F8-37 } \\
\end{array}$ & $\overline{~ H 2 F 8-72 ~}$ & H10F10-36 & $\begin{array}{l}\text { H10F10-54 } \\
\end{array}$ \\
\hline & & \multicolumn{4}{|l|}{ XRR } \\
\hline & $\begin{array}{l}\text { Film thickness } f \\
(\mathrm{~nm})\end{array}$ & 90 & 74 & 87 & 14 \\
\hline \multicolumn{6}{|l|}{$T_{\text {ann }}\left({ }^{\circ} \mathrm{C}\right)$} \\
\hline 30 & Layer distance $d$ & -- & 2.68 & -- & $\left.(4.0)^{*}\right)$ \\
\hline 50 & $(\mathrm{~nm})$ & -- & 2.72 & $(4.1)^{*)}$ & $\left.(4.0)^{*}\right)$ \\
\hline 80 & & $\left.(2.8)^{*}\right)$ & 2.72 & 4.21 & $\left.(4.0)^{*}\right)$ \\
\hline 105 & & $\left.(2.8)^{*}\right)$ & 2.68 & 4.06 & $\left.(4.0)^{*}\right)$ \\
\hline 135 & & $\left.(2.8)^{*}\right)$ & 2.52 & 4.11 & $\left.(4.0)^{*}\right)$ \\
\hline 160 & & -- & (not calc.) & 4.06 & $\left.(4.0)^{*}\right)$ \\
\hline & & \multicolumn{4}{|l|}{ GIWAXS } \\
\hline all $T_{\text {ann }}$ & $\begin{array}{l}\text { Mean chain distance } \\
\left\langle d_{\text {lat }}\right\rangle(\mathrm{nm})\end{array}$ & 0.547 & 0.537 & $\left.(0.487)^{*}\right)$ & -- \\
\hline$T_{\text {live }}\left({ }^{\circ} \mathrm{C}\right)$ & & \multicolumn{4}{|l|}{ GISAXS } \\
\hline 30 & Layer distance $d$ & -- & -- & 4.72 & 4.7 \\
\hline 84 & (nm) & -- & $<2.8^{* * *}$ & 4.69 & 4.7 \\
\hline $105 . .190 . .90$ & & -- & -- & -- & -- \\
\hline 84 & & -- & -- & 4.80 & 4.8 \\
\hline 66 & & -- & 2.9 & 4.76 & 4.7 \\
\hline 30 & & $<2.8^{* *)}$ & 2.86 & 4.52 & 4.5 \\
\hline
\end{tabular}

of detector area 
In contrast, thin films of the copolymers with H2F8 side chains do not show pronounced layer generation. After the temperature program, a Bragg reflection on the detector scan at $d=2.89$ $\mathrm{nm}$ appears. The reasons for the considerably lower tendency to generate layered structures are the same as explained also for the results of XRR and GIWAXS in the subsequent annealing mode. All film data are summarized in Table III.

\section{CONCLUSION AND OUTLOOK}

Temperature-dependant X-ray scattering methods are ideal for comparative investigations of bulk and film scattering parameters of copolymers with SF side chains and their phase separation behaviour. SAXS/WAXS bulk experiments up to $170{ }^{\circ} \mathrm{C}$ (heating/cooling cycles) were performed for basic structure information. The X-ray measurements proved formation of semifluorinated layers with $d$-spacing of $3.1 \mathrm{~nm}$ for P(MMA/SFMA-H2F8) and $4.4 \mathrm{~nm}$ for $\mathrm{P}(\mathrm{MMA} / \mathrm{SFMA-H10F10)}$ and distinct thermal extension behaviour.

As-prepared films with variable film thicknesses show very low roughness and good reproducibility. In the temperature range of side chain melting $T_{\mathrm{m}}$ the generation of layered structures starts in the case of H10F10 side chains, whereas films of H2F8 copolymers show an increasing roughness only for samples with lower SF content. Samples with higher content of SFMA-H2F8 comonomer show a layered structure, too. Temperatures higher than $T_{\mathrm{g}}$ degrade the film parameters. This tendency is stronger for copolymers with H2F8 side chains. Concerning the phase behaviour in bulk, the SF side chain amount and their specific fluorine content control the self-organization tendency of the semifluorinated side chains. Additionally to the structure expected from bulk behaviour, thin films are characterized by geometric confinements and orientation effects depending on the film thickness. An expansion of the existence area of layered structures could not be observed. Using GISAXS, it could be found that the spin-coated films are not in equilibrium. Only after subsequent heating an improvement of the aligned side chains perpendicularly to the film surface takes place. Also in the cooling cycle (after polymer melting and isotropization) a highly ordered/oriented structure of the film will be generated again driven by the strong incompatibility between main and side chains.

The $d$-values of the SF sublayers indicated a head-to-head arrangement of SF side chains without interdigitation and tilt in case of H2F8 side chains, whereas H10F10 copolymers show strong interdigitation of the fluorinated part of the side chains as well as a small tilt relatively to the main chain sublayer.
The behaviour found here for random copolymers is quite similar to that of diblock copolymers of PMMA and PSFMA-H2F8 with comparable composition. Random copolymers with identical side chain architectures show a weaker tendency relating the SF sublayers. Detailed X-ray scattering investigations have to be performed to clarify the effects of constrained dimensions onto a varied morphology in very thin films.

\section{ACKNOWLEDGEMENTS}

We thank all colleagues of IPF participating in synthesis and characterization of the examined copolymers. We gratefully acknowledge financial support by and participation in the former EU Network of Excellence "NANOFUN-POLY" and by the German Exchange Service (DAAD). We thank HASYLAB @ DESY Hamburg for the opportunity to carry out scattering experiments, especially the beamline operators Dr. Jan Perlich and Dr. Sergio Funari for excellent assistance. 


\section{References:}

Appelhans, D., Wang, Z.-G., Zschoche, S., Zhuang, R.-C., Häußler, L., Friedel, P., Simon, F., Jehnichen, D., Grundke, K., Eichhorn, K.-J., Komber, H., and Voit, B. (2005). "Bulk and surface Jehniche, D.., Gr, $Z$-G., $Z$ sche, 1664.
properties of maleimide copolymers. Effect or fluorinated side chains, , Macromolecules 38, 1655 -

Busch, P. (2003). „Lamellare Orientierung in dünnen Diblockcopolymerfilmen - Strukturen an der Filmoberfläche und im Filminneren“", PhD Thesis, Universität Leipzig (Germany).

Busch, B., Rauscher, M., Smilgies, D-M., Posselt, D. and Papadakis, C. M. (2006). "Grazingincidence small-angle $\mathrm{x}$-ray scattering (GISAXS) as a tool for the investigation of thin approximation". J. Appl. Cryst. 39, 433-442.

Busch, P., Krishnan, S., Paik, M., Toombes, G. E. S., Smilgies, D.-M., Gruner, S. M., and Ober, C. K (2007). "Surface induced tilt propagation in thin films of semifluorinated liquid crystalline side chain block copolymers", Macromolecules 40,81-89.

Friedel, P., Pospiech, D., Jehnichen, D., Bergmann, J., and Ober, C. K. (2000). „Polyesters with semifluorinated side chains: A proposal for the solid state structure“, J. Polym. Sci., Part B Polym. Phys. 38, 1617-1625.

Galli, G., Martinelli, E., Chiellini, E., Ober, C. K., and Glisenti, A. (2005). "Low surface energy characteristics of mesophase-forming $\mathrm{ABC}$ and $\mathrm{ACB}$ triblock copolymers with fluorinated $\mathrm{B}$ blocks", Mol. Cryst. Liq. Cryst. 441, 211-226.

Gopalan, P., Andruzzi, L., Li, X., and Ober, C. K. (2002). "Fluorinated mesogen-jacketed liquidcrystalline polymers as surface-modifying agents: Design, synthesis and characterization", Macromol. Chem. Phys. 203, 1573-1583.

Gottwald, A., Pospiech, D., Jehnichen, D., Häußler, L., Friedel, P., Pionteck, J., Stamm, M., and Floudas, G. (2002). „Self-assembly and viscoelastic properties of semifluorinated polyesters “ Macromol. Chem. Phys. 203, 854-861.

Grundke, K., Pospiech, D., Kollig, W., Simon, F., and Janke, A. (2001). „Wetting of heterogeneous surfaces of block copolymers containing fluorinated segments", Colloid Polym. Sci. 279, 727735

Höpken, J., and Möller, M. (1992). "Low surface energy polystyrene”, Macromolecules 25, 1461 1467.

Jehnichen, D., Pospiech, D., Janke, A., Friedel, P., Häußler, L., Gottwald, A., Kummer, S., Kollig, W., and Grundke, K. (2001). „Bulk and surface structure of semifluorinated polyesters”, Mater. Sci. Forum 378-381, 378-382.

Jehnichen, D., Pospiech, D., Häußler, L., Friedel, P., Gottwald, A., and Kummer, S. (2004). „Selforganization in semifluorinated polymers“, Mater. Sci. Forum 443-444, 223-226.

Jehnichen, D., Pospiech, D., Häußler, L., Friedel, P., Funari, S. S. Tsuwi, J., and Kremer, F. (2007). „Microphase separation in semifluorinated polyesters“, Z. Kristallogr. Suppl. 26, 605-610.

Jehnichen, D., Pospiech, D., Friedel, P., and Funary, S. S. (2011). „Semifluorinated PMMA/PSFMA diblock copolymers with multiple phase separation", Z. Kristallogr. Proc. 1, 487-492.
Li, X., Andruzzi, L., Chiellini, E., Galli, G., Ober, C. K., Hexemer, A., Kramer, E. J., and Fischer, D. A. (2002). „Semifluorinated aromatic side-group polystyrene-based block copolymers: Bulk structure and surface orientation studies", Macromolecules 35, 8078-8087.

Mitchell, G. R. and Windle, A. H. (1985). "Diffraction from thermotropic copolyester molecules", Colloid Polym. Sci. 263, 230-244.

Müller-Buschbaum, P. (2003). ,,Grazing incidence small-angle X-ray scattering: an advanced scattering technique for the investigation of nanostructured polymer films", Anal. Bioanal. Chem. 376, 3-10.

Müller-Buschbaum, P. (2009). "A Basic Introduction to Grazing Incidence Small-Angle X-Ray Scattering". Lect. Notes Phys. 776, 61-89.

Pospiech, D., Jehnichen, D., Gottwald, A., Häußler, L., Scheler, U., Friedel, P., Kollig, W., Ober, C. K., Li, X., Hexemer, A., Kramer, E. J., and Fischer, D. A. (2001). „Investigation of the microphase separation in semifluorinated polyesters“, Polym. Mater. Sci. Eng. 84, 314-315.

Pospiech, D., Komber, H., Voigt, D., Jehnichen, D., Häußler, L., Gottwald, A., Eckstein, K., Baier, A., and Grundke, K. (2003a). ,Synthesis and characterization of semifluorinated polymers and block copolymers", Macromol. Symp. 199, 173-186.

Pospiech, D., Jehnichen, D., Gottwald, A., Häußler, L., Kollig, W., Grundke, K., Janke, A., Schmidt, S., and Werner, C. (2003b). "Surface structure of fluorinated polymers and block copolymers", Surf. Coating. Int. B, Coating. Trans. 86, 43-52.

Pospiech, D., Häußler, L., Jehnichen, D., Kollig, W., Eckstein, K., and Grundke, K. (2003c). "Bulk and surface properties of blends with semifluorinated polymers and block copolymers", Macromol. Symp. 198, 421-434.

Rauscher, M., Salditt, T. and Spohn, H. (1995). "Small-angle X-ray scattering under grazing incidence: the cross section in the distorded-wave Born approximation", Phys. Rev. B 52, 1685516863.

Tsuwi, J., Pospiech, D., Jehnichen, D., Häußler, L., and Kremer, F. (2007). "Molecular dynamics in semifluorinated side-chain polysulfone studied by broadband dielectric spectroscopy", J. Appl. Polym. Sci. 105, 201-207.

Wang, J., Mao, G., Ober, C. K., and Kramer, E. J. (1997). "Liquid crystalline, semifluorinated side group block copolymers with stable low energy surfaces: Synthesis, liquid crystalline structure, and critical surface tension", Macromolecules 30, 1906-1914. 